\title{
Karpal kemikler ve el (metakarp ve falanks) kırıkları ve çıkıkları
}

\author{
Carpal bones and hand (metacarpal and phalanx) fractures and dislocations
}

\author{
Seyran Kılınç \\ Cumhuriyet Üniversitesi Tıp Fakültesi, Ortopedi ve Travmatoloji Anabilim Dalı, Sivas
}

\begin{abstract}
Çocuk ve ergenler için el, sıradan bir yaralanma alanıdır. Yeterli radyografik görüntüleme ile birlikte kapsamlı bir anemnez ve fizik muayene gereklidir. Küçük çocuklarda en yaygın olan yaralanma mekanizması, kapı arasında elin kalmasından kaynaklanan ezilme yaralanmaları iken, gençlerdeki kırıkların çoğu eğlence sporlarından kaynaklanır. Bu yaralanmalarda doğru teşhis ve zamanında müdahale, optimal el işlevleri için temel yapıtaşı oluşturmaktadır. Metakarpal ve falangeal kırıkların, göreceli olarak küçük boyutlarından dolayı radyografik tanısında zorluklar olması, tedavide potansiyel gecikmelere yol açabilir. Uygun bir sonuç elde etmek için erken tanı ve hızlı teşhis gereklidir. Ortak kırık yerlerinin ve modellerinin tanınması, hızlı ve uygun tedavinin sağlanmasında çok önemlidir.
\end{abstract}

Anahtar sözcükler: çocuk; el; kırıklar; çıkıklar
The hand is a common site of injury in children and adolescents. A thorough history and physical examination along with adequate radiographic imaging are essential. The most common mechanism of injury in younger children is crush injury resulting from the hand caught in a closing door while most fractures in teenagers result from recreational sports. Accurate diagnosis and timely management of these injuries continue to be the cornerstone of optimal hand functions. Metacarpal and phalangeal fractures can be difficult to diagnose at radiography due to their relatively small size, leading to potential delays in treatment. Early recognition and prompt diagnosis are necessary to achieve a satisfactory outcome. Recognition of common fracture locations and patterns is essential in ensuring prompt and appropriate treatment.

Key words: children; hand; fractures; dislocations
Ç. ocuklar, farklı nedenlerden dolayı el yaralanmalarına yatkındırlar. Bu durum sıklıkla, çocuklardaki öğrenme içgüdüsünden ve tehlikeye cesaretli yaklaşımdan dolayıdır. ${ }^{[1]}$

Çocuk hastalarda yaralanmalar iki aşamalı dağılım gösterir. Özellikle, yeni yürümeye başlayan çocuklar ve ergenlik dönemi yaş grubunda sıklıkları fazladır. ${ }^{[1-2]}$

Küçük çocuklarda görülen yaralanmalar daha sıklıkla ezilme ve çarpma yaralanmaları şeklinde olurken, ergenlik döneminde bu yaralanmalar sportif faaliyetler ve fiziksel kavgalar sırasında olur. ${ }^{[1]}$

Kırıklar erkeklerde kızlara göre daha sık görülürken, bu farklılık yaşla birlikte artar. ${ }^{[2]}$

Büyümekte olan çocuklarda el anatomisinin ve kemikleşme merkezlerinin bilinmesi; el yaralanmalarının değerlendirmesi ve tanı koyulmasında hayati önem arz eder. Yaralanmanın değerlendirilmesinde birincil araç radyografidir. Radyolojik bulguların yanlış değerlendirilmesi tanı ve tedavide aksaklıklara yol açabilir (Şekil 1). ${ }^{[3]}$

\section{SKAFOID KIRIĞI}

Çocuk skafoid kırıkları, el ve el bileği kırıklarının sadece \%3'ünü oluştursa da, bu yaş grubunda en sık görülen karpal kırıklardır. ${ }^{[1,4]}$ Çocuk hastalarda tanı ve tedavi, büyük ölçüde karpal kemiklerin kemikleşmesi ve kanlanmasının anlaşılmasına bağlıdır. Skafoidin kemikleşme merkezi 4-5 yaşlarında görülmeye başlar ve 13-15 yaşlarında kemikleşmesi tamamlanır. ${ }^{[5]}$ Kırıklar, altı yaşından önce nadiren tanımlanır, çünkü sadece kıkırdak yapıdadır. Ancak, sonraki her yıl kırıkların insidansında artış olur ve yaklaşık 15 yaşında zirve yapar. ${ }^{[6]}$

- Illetişim adresi: Dr. Seyran Kılınç, Cumhuriyet Üniversitesi Tıp Fakültesi Hastanesi Ortopedi ve Travmatoloji Anabilim Dalı, 58140 Kampüs, Sivas Tel: 0531 - 7930068 e-posta: seyrankilinc@hotmail.com

- Geliș tarihi: 2 Subat 2019 Kabul tarihi: 2 Subat 2019 


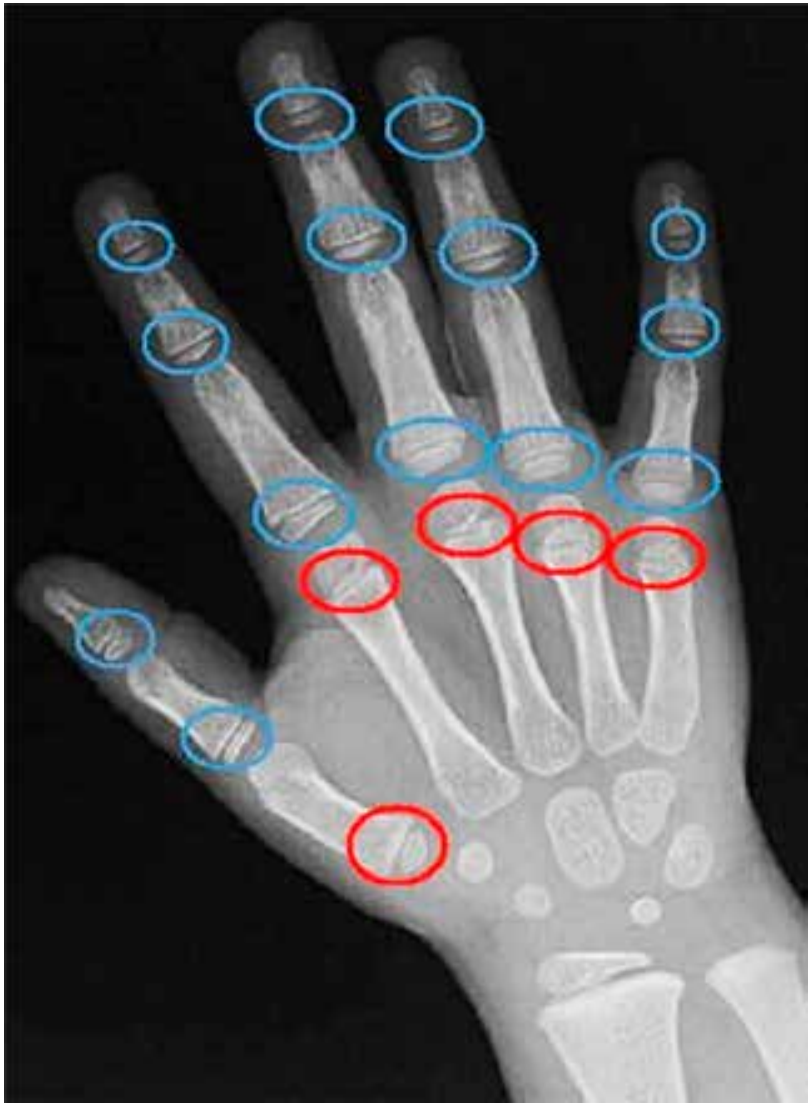

Şekil 1. Dört yaşındaki çocukta metakarp (kırmızı) ve falankstaki (mavi) epifız plağının anatomik yerlerinin ön-arka grafideki görüntüsü. 1. Metakarp epifiz plağı diğer metakarplara göre farklılık göstererek metakarpın proksimalinde yer almaktadır.

D'Arienzo, çocuğun yaşını ve tahmin edilen kemikleşme derecesini dikkate alacak şekilde, kırıkları üç gruba ayırmıştır. Tip 1 lezyonlar, tipik olarak sekiz yaşından küçük çocuklarda görülür ve skafoidin bel bölgesinde kemikleşme merkezinin proksimalinde oluşan tamamen kondral yaralanmalardır. Bu kırıklar nadirdir ve sıklıkla tanı için manyetik rezonans (MR) görüntüleme gerektirir. Tip 2 lezyonlar, kemikleşme süreci bel bölgesinden oluşmaya başlamış 8-11 yaş çocuklarda olup, kırıklar osteokondraldir ve uygun şekilde immobilizasyonla kolayca iyileşir. Tip 3 lezyonlar, 12 ve daha büyük yaştaki ergenlerde en sık rastlanan kırıklardır. Bu yaşta, skafoid neredeyse tamamen kemikleşmiş olduğundan, erişkin popülasyonla benzer davranış gösterir. ${ }^{[7]}$ Pediatrik skafoid kırığının geriye dönük bir analizinde, \%71'inin bel bölgesinde \%23'ünün distal uçta ve \%6'sının da proksimal uçta oluştuğu bulunmuştur. ${ }^{[7]}$

Skafoid kırıklarının \%13-30'unda başlangıç radyografileri normaldir ${ }^{7-9]}$. Çoğu yazar, tedavinin seyrini belirlemek için iki hafta boyunca başparmak destekli atel yapıp tekrar görüntüleme yapılmasını önermektedir. Kısa veya uzun kol alçı konusunda çok az fikir birliği olmakla birlikte, iki hafta sonra çekilen radyografiler normal ve çocuğun klinik bulguları gerilemişse, daha fazla immobilizasyon önerilmez. ${ }^{[7-9]} \mathrm{MR}$, yaralanmadan kısa bir süre sonra bir kırığı dışlamak için kullanılabilir. Illk 10 gün içinde çekilen MR bulgularının negatif bulunması, hastaların \%58'inde immobilizasyon sürecini azaltmıştır ${ }^{[10]}$.

Yer değiştirmemiş distal uç kırıkları en iyi ve hızlı iyileşen kırıklar olup, 4-8 hafta alçı tedavisi ile kaynama gerçekleşir. Bel kırıklarının da iyileşme süresi 5-16 hafta sürebilmektedir. ${ }^{[7]}$ Kaynamayan kırıklar, gecikmiş tanı konulan kırıklar, yetersiz immobilizasyon ve kaymış kırıklarda kaynama oranını arttırmak için cerrahi tedavi önerilir. Volar yaklaşımla otolog kemik grefti konularak Kirschner teli (K-teli) veya başsız kompresyon vidası ile kemik tespiti, kaynamamış kırıklar için kullanılır. ${ }^{[4]}$

\section{LUNATUM KIRIĞI}

Bu kırıklar oldukça nadir görülmekle birlikte bunların çoğu literatüre, perilunat çıkık veya izole lunat çıkığı şeklinde yansımıştır. ${ }^{[11-12]}$

Tanı ve tedavi atlanılan hastalarda, uzun dönem sonuçlarında fonksiyon bozukluğu ve kronik el bileği ağrısına neden olur. ${ }^{[13]}$ Tedavisinde, acil kapalı redüksiyon sonrasında skafoid kırığı ve skafolunat eklem stabilizasyonu için K-teli ile tespit önerilir. ${ }^{[5]}$

\section{KAPITATUM KIRIĞI}

Kapitatum kırıkları çocuk karpal kemik kırıkları arasında 2. sıklıkla görülmesine karşın, izole kırıkları oldukça nadirdir. ${ }^{[14]}$ Gerçek görülme sıklığı bilinmemektedir, çünkü direkt grafide görünmeyebilir ve immobilizasyon olmadan iyileşebilir. Tanıda gecikmeler olabilir. ${ }^{[15]}$

Bu kırıklar, yüksek enerjili travmalarda, hiperekstansiyonda distal radius ve lunat kemiğin baskısı ile oluşur. Kapitatum kırıkları, özellikle skafoid kemik olmak üzere, diğer karpal kemiklerle birliktelik gösterir. EI bileğinin aşırı dorsifleksiyonu sonrasında kapitatum başının dönmesi sonucu skafoid bel bölgesi ve kapitatum boyunda oluşan bu kırık, skafokapitat sendromu olarak adlandırılır. ${ }^{[16-18]}$

\section{PISIFORM KIRIĞı}

Pisiform yaralanmaları nadir yaralanmalardır ve literatürde genellikle distal radius kırığı ile birlikte görülen çıkık olgu sunumları şeklinde yayınlarda mevcuttur. ${ }^{[19-20]}$ 
Genel olarak ezilme yaralanmaları gibi direkt travmalarla olabilmekle birlikte, fleksör karpi ulnaris tendonunun maksimum gerilmesi ile palmar-fleksiyondaki el bileğinin zorlu dorsifleksiyonundan kaynaklanan dolaylı bir mekanizma ile de gerçekleşebilir. Direkt grafiler tanı için yeterli olmakla birlikte, bazen oblik grafiler de gerekebilir. ${ }^{[5]}$ Üç-dört hafta redüksiyon sonrası alçı tedavisi ile immobilizasyon önerilmekle birlikte, yaralanmanın diğer karpal kemiklerle birlikteliği unutulmamalıdır.

\section{HAMATUM KIRIĞI}

Hamatum kırıkları, özellikle açık el üzerine düşmelerde ulnar kenara gelen kuvvetlerin etkisiyle ezilme yaralanmalarında veya direkt darbeler sonucunda oluşabilir. Genellikle hamatumun çentik kısmı kırılır. Tanı, klinik olarak hamatum çentik üzerinde hassasiyet olması ve radyolojik olarak bilgisayarlı tomografi (BT) ile konulur; 4. ve 5. metakarp bazis kırıkları ile hamatum gövde kırıkları, Lisfrank tipi yaralanmalara benzer birliktelik gösterebilir. ${ }^{[5]}$

\section{TRIKUETRUM KIRIĞI}

Oldukça nadir görülen bu kırıklar, özellikle 11-13 yaş çocuklarda, el bileğinin hiperekstansiyon ve ulnar deviyasyonda zorlanmasıyla oluşur. ${ }^{[21]}$

Bu kırıkların görülme sıklığının daha fazla olduğu tahmin edilmekle birlikte, travma sonrası hastalar genellikle bağ yaralanması, ulna ve radius Tip 1 epifiz kayması olarak değerlendirildiğinden, sıklıkla tanı konulamamaktadır. Distal ulna ve trikuetrum üzerinde hassasiyet mevcuttur. Tanı için oblik grafiler ve traksiyon grafilerine ihtiyaç duyulabilir. Yaralanmada, ulnar kolonu içine alan trikuetrolunat bağ ve triangular fibrokartilaj kompleks hasara uğramış olabilir. Bu hastalara 3-4 haftalık alçı immobilizasyonu uygulanır. ${ }^{[5]}$

\section{TRAPEZIUM VE TRAPEZOIDEUM KIRIĞI}

Çok nadir görülen bu karpal kemik kırıkları direkt travma veya el bilek hiperekstansiyon zorlamaları ile oluşabilmektedir. Kısa kol alçısı ile tedavi edilir. ${ }^{[5,22]}$

\section{METAKARP KIRIKLARI VE ÇIKIIKLARI}

Tüm çocuk el kırıklarının \%10-35'ini oluşturan metakarpal kırıklar, genellikle 13-16 yaş arasında ve çoğunlukla spor yaralanmaları neticesinde oluşur. ${ }^{[23]}$

Metakarp kırıkları; boyun, cisim, baş ve bazis kırıkları şeklinde, anatomik bölgesine göre sınıflandırilır ${ }^{[1]}$.
Metakarp bazis kırıkları bu kırıkların \%13-20'sini oluşturur. ${ }^{[2]}$ Sıklıkla 5. metakarpta görülür. Çoğu metakarp bazis kırı̆̆ı, transvers tipte ve aksiyel yüklenme sonucunda oluşur. Bu kırıklar, dikkatli değerlendirme yapılarak, özellikle ezilme yaralanmalarında kompartman sendromu açısından sıkı takip edilmelidir. ${ }^{[24]}$

Karpometakarpal (KMK) eklem çıkı̆̆ı, çocuklarda nadir görülen yaralanmalardır. Literatürde sınırı sayıda bildirimler mevcuttur. ${ }^{[25]}$ Eklemdeki çıkık, özellikle metakarp bazis yaralanması sonucunda oluşur. Aşırı şişlik nedeniyle, KMK eklem çıkığı ve bazis kırığı muayenede gözden kaçabilir. Aynı nedenle ayrıca, parmağın rotasyonel deformitesinin değerlendirilmesinde de zorluk yaşanılabilmektedir. Lateral grafide metakarpların üstüste binmesi nedeniyle radyolojik değerlendirme zor olduğundan, oblik grafilere ihtiyaç duyulabilir. Ayrıca, eklem içi kırıkların değerlendirilmesinde BT yardımcı olabilir. Ayrılmamış ve minimal yer değiştirmiş eklem dışı kırıklar, 3-4 haftalık alçı-atel yapılarak konservatif tedavi edilir. Başlangıçta, kompartman sendromu açısından uyanık olunmalıdır. KMK eklem çıkıkları ve yer değiştirmiş bazis kırıklar, kapalı olarak redükte edilemezse açık redüksiyon yapılmalıdır. Dorsal longitudinal insizyonla, hem iyi bir cerrahi görünüm sağlanıp hem de gerekirse fasyotomi için bu insizyon distale uzatılabilir. Redüksiyon sonrası stabilitesi değerlendirilen eklem çıkık ve kırıklarına gerekirse K-teli ile tespit yapılır. ${ }^{[24]}$

Metakarp cisim kırıkları karpal kemik kırıklarının \%10-14'ünü oluşturur. ${ }^{[26]}$ Özellikle torsiyonel kurvetler ile oluşur. En sık 3., 4. ve 5. metakarplarda görülür. Sıklıkla spiral tipte kırıklar nedeniyle oluşan rotasyon deformiteleri için dikkatli muayene edilmelidir. ${ }^{[3]}$ Kaymamış kırıklarda, şişlik takibi yapılarak alçı atel ile 4-6 hafta tedavi yapılır. Yer değiştirmiş ve instabil kırıklarda, kapalı veya açık redüksiyon yapılarak pinleme yapılmalıdır ${ }^{[24]}$.

Metakarp boyun kırıkları metakarpal kemik kırıklarının \%56-70'ini oluşturur. ${ }^{[26]}$ Ergenlik dönemi çocuklarda genelde kavga sonucunda oluşurken, daha küçük çocuklarda düşme ve spor yaralanmalarında oluşur ${ }^{[24]}$. En sık 5. metakarpta görülür. ${ }^{[2,26,27]}$ Yaralanma, aksiyel kuvvetler veya eğilme kuvvetlerinin etkisi ile metakarpın dorsale açılanması şeklinde oluşur. Rotasyonel deformite kontrol edilmelidir. Ayrıca, el üzerinde diş izi ve kontaminesi açısından dikkatli muayene yapılmalıdır. iki yönlü grafi radyolojik olarak yeterli olmakla birlikte, kırık kayma miktarının değerlendirmesinde bazen oblik grafiler de yardımcı olmaktadır. ${ }^{[24]}$

Ayrılmamış basit kırıklar, 3-4 haftalık atel uygulaması ile konservatif olarak tedavi edilir. Ayrılmış kırıklarda kapalı redüksiyon yapılır ve redüksiyon sonrası çoğu 
yazar, işaret parmağından küçük parmağa doğru sırasıyla $10^{\circ}-20^{\circ}-30^{\circ}-40^{\circ}$ 'lik açılanmaları kabul etmektedir. ${ }^{[2,24]}$ Rotasyon deformitesi tam olarak düzeltilmelidir. Şişlik izin verdiği sürece alçı yapılmalıdır, çünkü çocuklarda tedavi süresince atelin yararı kısa sürmekte ve çoğu zaman çocukların kollarından sıyrılmaktadır. Tedavi süresince redüksiyon kontrol edilmeli, şişlik gerilemesine bağlı redüksiyon kaybı olabileceği akılda tutulmalıdır. Klinik ve radyolojik iyileşme sağlanınca, dört hafta sonra alçı çıkarılır. Açık redüksiyon nadir gerekmekle birlikte, özellikle 2. ve 3. metakarpların stabil olmayan kırıklarında gerekebilir. Pinleme yapılan hastalarda dört hafta sonunda, kaynama olduktan sonra K-telleri çıkarılır. ${ }^{[24]}$

Metakarp epifiziyel yaralanmalar nadir görülen yaralanmalar olup, özellikle 5. metakarpta ve sıklıkla SalterHarris Tip II yaralanmaları olarak görülür. Ayrılmamış kırıklarda, eklem dışı metakarp boyun kırıkları gibi tedavi yapılmakla birlikte, ayrılmış kırıklarda açık redüksiyon ve parçanın boyutuna göre sütür, tel veya vida ile tespit gerekir. ${ }^{[24]}$

Metakarpofalangeal (MKF) eklem çıkığı, çocuk el çıkıkları arasında yaygın görülür. Sıklıkla başparmakta görülmekle birlikte, 2. parmak MKF eklem redüksiyonunda zorluk yaşanır. ${ }^{[24]}$ Falanks tipik olarak dorsale kayar ve MKF eklem hiperekstansiyonda görülür. Metakarp başı volarde kolayca ele gelebilir. Radyolojik olarak ön-arka grafide eklem aralığı geniş veya dar olabilir. Lateral grafide eklem hiperekstansiyonda görülebilir. Volar plak yırtılıp eklem arasında sıkışma yaparak redüksiyonu engelleyebilir. Düz traksiyon ve palmar bölgeden bası yapılarak redüksiyon gerçekleştirilir. Kapalı redükte olmayan olgularda açık redüksiyon gerekir. Redüksiyon ardından yaklaşık bir hafta alçı atel sonrası eklem hareket egzersizlerine başlanır. ${ }^{[24]}$

\section{FALANKS KIRIKLARI VE ÇIKIKLARI}

Çocuk ve gençlerde falankslar, eldeki en sık yaralanan kemiklerdir. Özellikle distal falanks ve proksimal falanks bazis kırığı şeklinde görülür. ${ }^{[28]}$ Sıklıkla 5. parmak ve başparmak etkilenir. ${ }^{[29]}$ Görülme sıklığı daha çok büyük çocukların sportif faaliyetlere başlaması ile artar. ${ }^{\left[{ }^{[0]}\right.}$ Küçük çocuklarda ise, daha çok ev içi yaralanmalar sorumlu tutulur. ${ }^{[28,29]}$ Çocuklarda falanksların kemik büyümesi proksimal uçtaki fizis plağı ile gerçekleşir ve bu plaklar 14-16 yaşa kadar açık kalır. Bu fiziyel merkezleri bilmek önemlidir. Çünkü, çoklu falanks yaralanmalarında redüksiyon denemeleri sırasında hasar oluşabilir. Ayrıca, mineralize olmayan fizis, çevre bağ dokusundan ve olgun kemik yapılardan daha zayıftır. Bu durum, fizisi travma sırasında hassas hale getirir. ${ }^{[6]}$
Falanks cisim kırı̆̆ı diğer falanks kırıklarına göre daha az görülür. ${ }^{[31]}$ Muayene bulguları bazen çok belirleyici olmayabilir. Açısal ve rotasyonel deformiteler için dikkatli muayene yapılmalıdır. Ayrılmamış veya minimal yer değiştirmiş kırıklarda, 3-4 haftalık atelleme sonrası erken aktif harekete başlanmalıdır. ${ }^{[6]}$ Kaymış spiral ve oblik kırıklarda, kapalı redüksiyon gerçekleştirilerek daha sıkı bir alçılama yapılmalıdır. Redüksiyon devamlılığı yeterli olmayan hastalarda tespit gerekebilir. ${ }^{[28]}$

Proksimal falanks bazis kırığı, yaygın olarak, MKF eklemin aşırı abduksiyon hareketi sonucu oluşan kuvvetler ile gerçekleşir. En sık Salter-Harris Tip II kırığı şeklinde görülürken, sadece metafiz kırı̆gı şeklinde de oluşabilir. ${ }^{[28]}$ Salter-Harris Tip III yaralanmaları, özellikle proksimal ve orta falanks bazis kırıkları şeklinde, ergenlik dönemi tırmanma atletlerinde görülme eğilimindedir. ${ }^{[32]}$ Bazis kırıklı hastalarda, yumuşak doku ve fleksör tendonun kırık parçaları arasına girdiği nadir durumlarda, açık redüksiyon gerekebilir. ${ }^{[28]}$

Falanks boyun kırıkları, tedavi ve sonuçları açısından problemli olgulardır. Ağırlıklı olarak, erken çocukluk döneminde kapı arasında parmağın kalması ile oluşur. Başa ait parça kollateral bağa yapışık kalır ve ekstansiyonda rotasyona uğrar. ${ }^{[1]}$

Radyolojik değerlendirme etkilenen parmağa göre izole edilmedir. Lateral grafi, dorsal kaymaları değerlendirmede dikkatli yorumlanmalıdır. ${ }^{[28]}$ Tedavi, kırık hattının kayma durumuna göre değerlendirilir. Kaymamış kırıklar 3-4 haftalık atel ile konservatif tedavi edilir. ${ }^{[33]}$ Yer değiştirmiş kırıklar sagittal planda instabil olduğu için, distal parça dorsale kaymış olur. $\mathrm{Bu}$ durum, fleksiyonda mekanik engel oluşturur. Bu nedenle, kaymış ve açılanmış kırıklar kapalı redüksiyon ve pinleme gerektirir. ${ }^{[33]}$ Perkütan pinleme yapılan hastalarda, sadece kapalı redüksiyon yapılan hastalara göre, kaynamama ve yanlış kaynama riski daha az olarak izlenmiştir. Yeniden şekillenme oranının, dorsal olarak yer değiştirmiş sagittal plandaki deformitede koronal deformiteye göre daha yüksek olması, olasıdır. Konservatif tedavi edilen hastalarda eklem uyumu iyi olmalı, koronal deformite olmamalı, yeniden şekillenmenin uzun süreceği bilgisi hasta yakınları ile paylaşılmalıdır. ${ }^{[28]}$ Falanks boyun kırığı, diğer falanks kırıklarına göre, malpozisyon, hareket kısıtlılığı ve osteonekroz açısından daha yüksek risklere sahiptir (Şekil 2). ${ }^{[34]}$

Falanks kondiller kırıklar eklemi içine alır ve bu kırıklar; lateral kopma kırıklar, unikondiller, bikondiller ve subkondral tipte kırıklar olarak karşımıza çıkar. ${ }^{[1,3,28]}$ Bu kırıkların tedavisi, başlangıçta basit yumuşak doku yaralanması gibi yanlış yorumlanarak gecikebilmektedir. ${ }^{[28]}$ Kırığı tanımlamak için gerekirse oblik grafiler çekilmelidir ${ }^{[6]}$. 


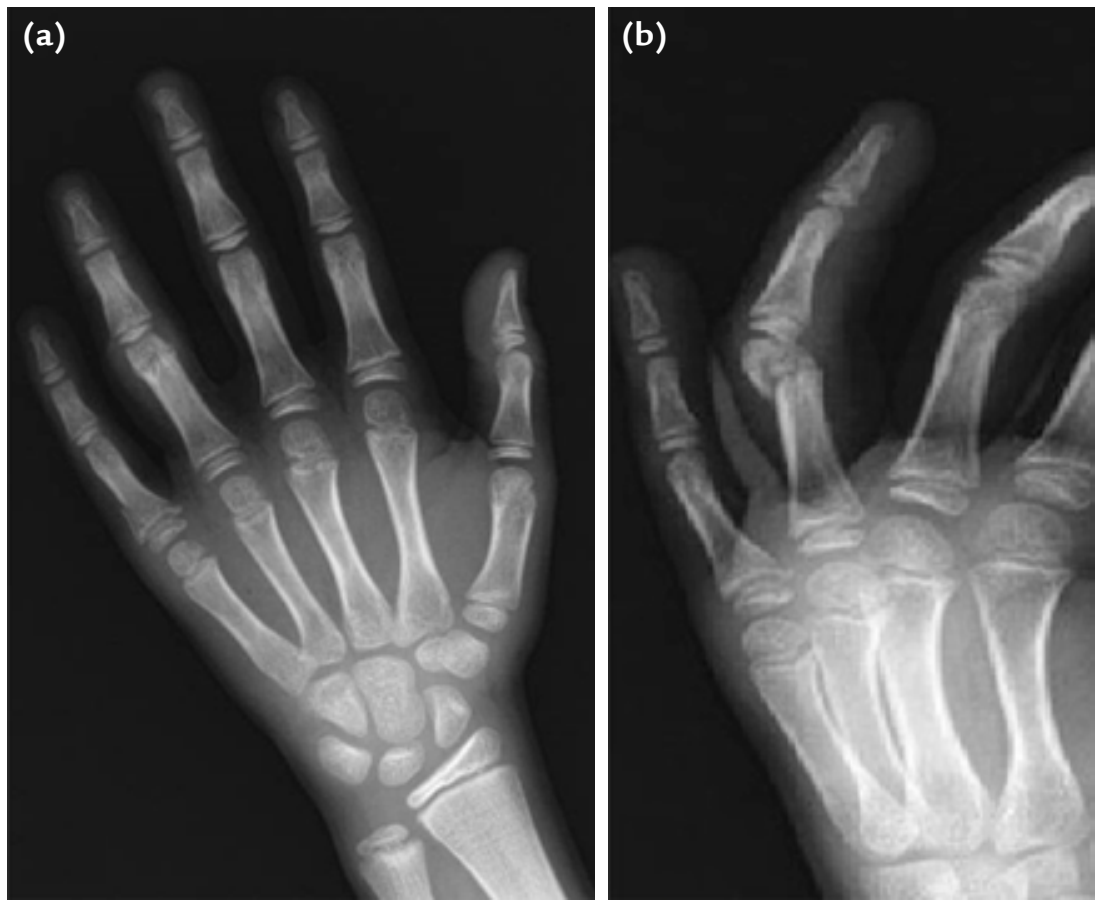

Şekil 2. a-e. On yaşındaki çocukta 4. parmak proksimal falanks boyun kırığı: hastanın acil servisteki iki yönlü grafileri (a, b) kapalı redüksiyon sonrasında dorsale açılanan kemik parçanın lateral grafisi (c) kapalı redüksiyon ve pinleme yapılan hastanın ameliyat esnasındaki skopi görüntüleri (d, e).
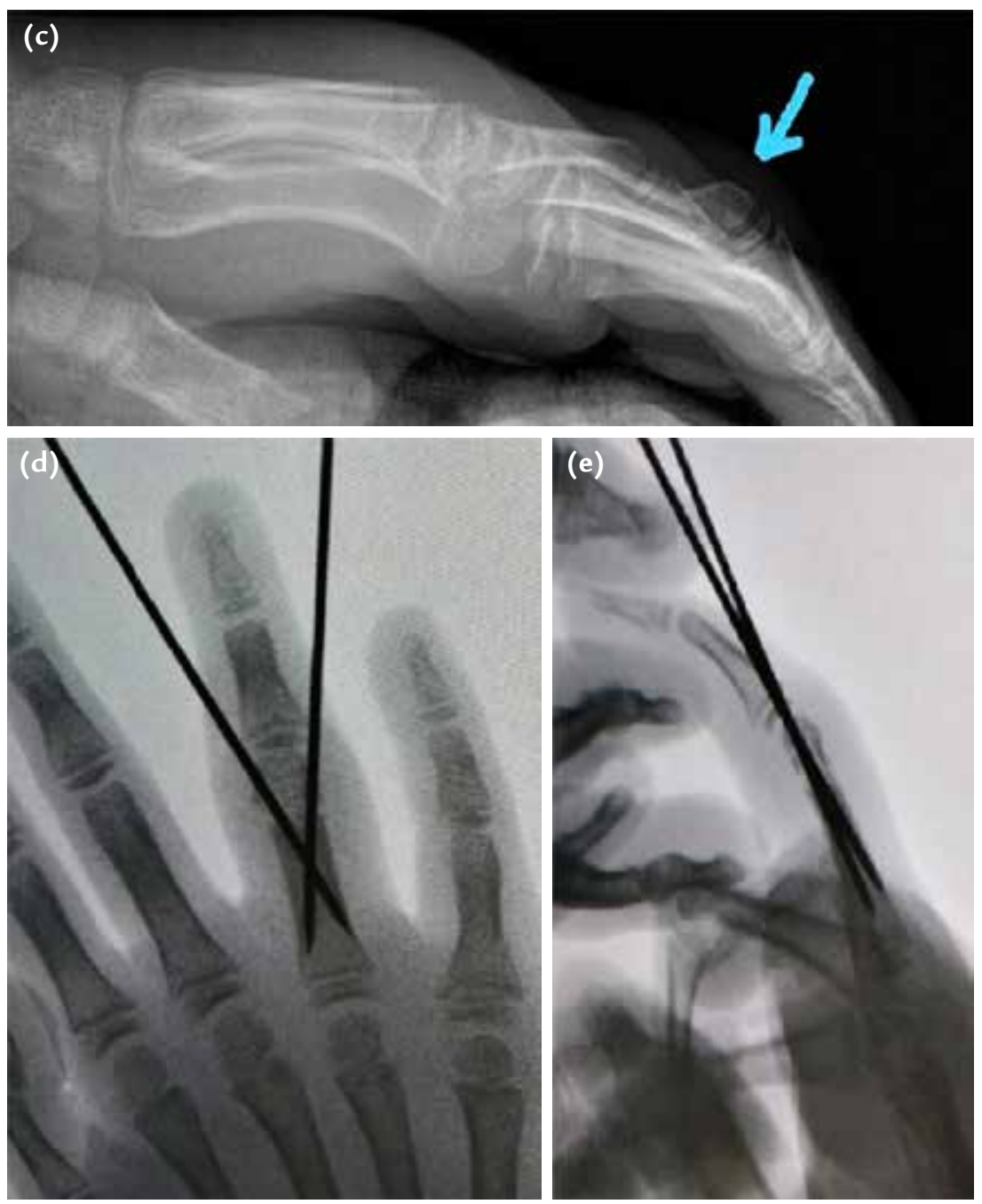
Yer değiştirmemiş kırıklar, haftalık grafi kontrolünde konservatif tedavi edilir. Başarılı bir tedavi için eklem stabilitesi ve anatomik dizilimi önemlidir. ${ }^{[1]}$

Yer değiştirmiş kırıkların tedavisinde, kapalı veya açık redüksiyon uygulanarak pinleme yapılır. Osteonekroz açısından gerekmedikçe, açık redüksiyondan kaçınımalıdır. Tespit yönünden birçok yöntem sunulmuştur ve yapılan son çalışmalarda bunlar arasında biyomekanik olarak anlamlı farklılıklar bulunmamıştır. ${ }^{[28]}$

Distal falanks kırıkları fiziyel ve ekstra-fiziyel olarak ayrılabilir. Ekstrafiziyel yaralanmalar sık görülür ve basit yaralanmalardan, tırnak yatağı laserasyonu ile birlikte cisim kırığına kadar ilerleyebilir. Distal falanks bazis kırıkları eklem içi ve dışı olabilir. ${ }^{[1]}$

Eklem içi olanlar, ekstansör veya fleksör tendon kopma kırıkları şeklinde olabilir. Ekstansör tendon yaralanmaları daha sık görülür ve bunlar ani kuvvetli fleksiyon zorlamalarında gerçekleşir. Tendon gerilmesine bağlı olarak, kemik yapışma yerinden kopma şeklinde ayrılma gerçekleşir. Bu durum Mallet kırığı diye adlandırılır. ${ }^{[3]}$ Bu gerilme sırasında oluşan eklem dışı fiziyel ayrılma da Seymour kırığı olarak adlandırılır. ${ }^{[1]}$ Kırık tipi olarak Salter-Harris Tip I veya Tip II kırığıdır. Seymour kırığı, tırnak büyüme bozukluğu, enfeksiyon ve eklem hareket kaybı gibi yüksek oranda komplikasyonlara sahiptir. ${ }^{[35]}$

Hiperekstansiyon kuvveti, fleksör profundus tendonunun gerilmesine bağı kopma kırığı şeklinde yaralanmalara neden olabilir. Jersey kırı̆ı olarak da adlandırılan bu kırık tipi de, ağırlıklı olarak rakip oyuncunun formasının çekilmesi sonucuyla oluşmaktadır. ${ }^{[3]}$

Öykü ve muayene, tanıya kolay varılmasını sağlar. Tırnak yaralanması veya subungual hematom, kemik yaralanmasından şüphe uyandırmalıdır. Direkt grafiler, tanıyı netleştirmek ve kırık tipini belirlemek için iki yönlü çekilmelidir. Tedavide, yumuşak doku tamirinin en az kemik tamiri kadar önemli olduğunu bilmek gerekir. Çoğu distal falanks kırığı konservatif tedavi edilir. Geniş kayma gösteren stabil olmayan ekstra-epifiziyel kırıklar, \%50'den fazla epifizin dorsale yer değiştirmiş kırıkları, açık stabil olmayan redükte edilemeyen kırıklar ve Jersey kırık tiplerinde cerrahi tedavi gerekir. ${ }^{[1]}$

\section{KAYNAKLAR}

1. Kozin HK, Waters PM. Çocuklarda el ve el bileği kırık ve çıkıklar. İçinde: Beaty JH, Kasser JR, editörler. Başbozkurt M, Yıldız C, Çev. ed. Rockwood ve Wilkins, Çocuk Kırıkları. Ankara: Güneş Tıp Kitapevi; 2014. pp.225-91.

2. Valencia J, Leyva F, Gomez-Bajo GJ. Pediatric hand trauma. Clin Orthop Relat Res 2005;(432):77-86. Crossref

3. Sivit AP, DuPont EP, Sivit CJ. Pediatric hand injuries: Essentials you need to know. Emerg Radiol 2014;21(2):197-206. Crossref
4. Gholson JJ, Bae DS, Zurakowski D, Waters PM. Scaphoid fractures in children and adolescents: Contemporary injury patterns and factors influencing time to union. J Bone Joint Surg Am 2011;93(13):1210-9. Crossref

5. Goddard N. Carpal fractures in children. Clin Orthop Relat Res 2005;(432):73-6. Crossref

6. Nellans KW, Chung KC. Pediatric Hand Fractures. Hand Clin 2013;29(4):569-78. Crossref

7. D'Arienzo M. Scaphoid fractures in children. J Hand Surg Br 2002;27(5):424-6. Crossref

8. Evenski AJ, Adamczyk MJ, Steiner RP, Morscher MA, Riley PM. Clinically suspected scaphoid fractures in children. J Pediatr Orthop 2009;29(4):352-5. Crossref

9. Anz AW, Bushnell BD, Bynum DK, Chloros GD, Wiesler ER. Pediatric scaphoid fractures. J Am Acad Orthop Surg 2009;17(2):77-87. Crossref

10. Johnson KJ, Haigh SF, Symonds KE. MRI in the management of scaphoid fractures in skeletally immature patients. Pediatr Radiol 2000;30(10):685-8. Crossref

11. De Smet L, Fabry G, Stoffelen D, Broos P. Displaced fracture of the lunate in a child. Acta Orthop Belg 1993;59(3):303-5.

12. DeCoster TA, Faherty S, Morris AL. Case report. Pediatric carpal fracture dislocation. J Orthop Trauma 1994;8(1):768. Crossref

13. Kannikeswaran N, Sethuraman U. Lunate and perilunate dislocations. Pediatr Emerg Care 2010 Dec; 26(12):921-4. Crossref

14. Light TR. Carpal injuries in children. Hand Clin 2000;16(4):513-22.

15. Khoriati A, Jones C, Abdulkareem A, Ellahee N. Delayed identification of an isolated paediatric capitate fracture. Trauma Case Rep 2017:12:8-10. Crossref

16. Anderson WJ. Simultaneous fracture of the scaphoid and capitate in a child. J Hand Surg Am 1987;12(2):271-3. Crossref

17. Compson JP. Trans-carpal injuries associated with distal radial fractures in children: a series of three cases. J Hand Surg Br 1992;17(3):311-4. Crossref

18. Mazur K, Stevanovic M, Schnall SB, Hannani K, Zionts LE. Scaphocapitate syndrome in a child associated with a distal radius and ulna fracture. J Orthop Trauma 1997;11(3):2302. Crossref

19. Ashkan K, O'Connor D, Lambert S. Dislocation of the pisiform in a 9-year-old child. J Hand Surg Br 1998;23:26970. Crossref

20. Mancini F, De Maio F, Ippolito E. Pisiform bone fracturedislocation and distal radius physeal fracture in two children. J Pediatr Orthop B 2005;14(4):303-6. Crossref

21. Letts $M$, Esser D. Fractures of the triquetrum in children. J Pediatr Orthop 1993;13(2):228-31.

22. Wulff RN, Schmidt TL. Carpal fractures in children. J Pediatr Orthop 1998;18(4):462-5. Crossref

23. Godfrey J, Cornwall R. Pediatric Metacarpal Fractures. Instr Course Lect 2017;66:437-45.

24. Cornwall R. Finger metacarpal fractures and dislocations in children. Hand Clin 2006;22(1):1-10. Crossref

25. Gaillard J, Fitoussi F. Recurrent posttraumatic trapeziometacarpal joint dislocation in a child: A case report. Hand Surg Rehabil 2016;35(2):139-43. Crossref

26. Mahabir RC, Kazemi AR, Cannon WG, Courtemanche DJ. Pediatric hand fractures: a review. Pediatr Emerg Care 2001;17(3):153-6. Crossref 
27. Mayranpaa MK, Makitie O, Kallio PE. Decreasing incidence and changing patterns of childhood fractures: a populationbased study. J Bone Miner Res 2010;25(12):2752-9. Crossref

28. Abzug JM, Dua K, Bauer AS, Cornwall R, Wyrick TO. Pediatric Phalanx Fractures. J Am Acad Orthop Surg 2016;24(11):e174-83. Crossref

29. Yeh PC, Dodds SD. Pediatric Hand Fractures. Techniques in Orthopaedic 2009;24(3):150-62. Crossref

30. Naranje SM, Erali RA, Warner WC JR, Sawyer JR, Kelly DM. Epidemiology of pediatric fractures presenting to emergency departments in the United States. J Pediatr Orthop 2016;36(4):e45-8. Crossref

31. Vadivelu R, Dias JJ, Burke FD, Stanton J. Hand injuries in children: A prospective study. J Pediatr Orthop 2006;26(1):29-35. Crossref
32. Desaldeleer AS, Le Nen D. Bilateral fracture of the base of the middle phalanx in a climber: Literature review and a case report. Orthop Traumatol Surg Res 2016;102(3):409-11. Crossref

33. Park KB, Lee KJ, Kwak YH. Comparison between buddy taping with a short-arm splint and operative treatment for phalangeal neck fractures in children. J Pediatr Orthop 2016;35(7):736-42. Crossref

34. Huelsemann W, Singer G, Mann M, Winkler FJ, Habenicht R. Analysis of sequelae after pediatric phalangeal fractures. Eur J Pediatr Surg 2016;26(2):164-71. Crossref

35. Krusche-Mandl I, Köttstorfer J, Thalhammer G, Aldrian S, Erhart J, Platzer P. Seymour fractures: retrospective analysis and therapeutic considerations. J Hand Surg Am 2013;38(2):258-64. Crossref 